\title{
Progress in Payload Separation Risk Mitigation for a Deployable Venus Heat Shield
}

\author{
Brandon P. Smith ${ }^{1}$, Bryan C. Yount ${ }^{2}$ and Ethiraj Venkatapathy ${ }^{3}$ \\ NASA Ames Research Center, Moffett Field, CA, 94035, USA \\ Eric C. Stern ${ }^{4}$ \\ University of Minnesota, Minneapolis, MN, 55455, USA \\ Dinesh K. Prabhu ${ }^{5}$ \\ ERC Inc. at NASA Ames Research Center, Moffett Field, CA, 94035, USA \\ and \\ Daniel K. Litton ${ }^{6}$ \\ NASA Langley Research Center, Hampton, VA, 23681, USA
}

A deployable decelerator known as the Adaptive Deployable Entry and Placement Technology (ADEPT) offers substantial science and mass savings for the Venus In Situ Explorer (VISE) mission. The lander and science payload must be separated from ADEPT during atmospheric entry. This paper presents a trade study of the separation system concept of operations and provides a conceptual design of the baseline: aft-separation with a subsonic parachute. Viability of the separation system depends on the vehicle's dynamic stability characteristics during deceleration from supersonic to subsonic speeds. A trajectory sensitivity study presented shows that pitch damping and Venusian winds drive stability prior to parachute deployment, while entry spin rate is not a driver of stability below Mach 5. Additionally, progress in free-flight CFD techniques capable of computing aerodynamic damping parameters is presented. Exploratory simulations of ADEPT at a constant speed of Mach number of 0.8 suggest the vehicle may have an oscillation limit cycle near $5^{\circ}$ angle-ofattack. The proposed separation system conceptual design is thought to be viable.

\section{Nomenclature}

$\begin{array}{ll}C_{D} & =\text { drag coefficient } \\ C_{D 0} & =\text { parachute drag coefficient based on nominal area } \\ C_{D} A & =\text { parachute drag area } \\ \left(C_{D} A\right)_{p} & =\text { fully-open parachute drag area } \\ C_{L} & =\text { lift coefficient } \\ C_{m} & =\text { moment coefficient } \\ C_{m q} & =\text { aerodynamic pitch damping coefficient } \\ C_{x} & =\text { parachute canopy opening force coefficient at infinite mass } \\ d & =\text { leading body diameter } \\ D_{0} & =\text { parachute nominal diameter } \\ D_{p} & =\text { parachute projected diameter } \\ F_{p} & =\text { peak parachute opening force }\end{array}$

\footnotetext{
${ }^{1}$ Aerospace Engineer, Entry Systems and Vehicle Development Branch, M/S 229-1, Member AIAA.

${ }^{2}$ Aerospace Technologist, Experimental Facility Development, Engineering Systems Division, M/S 213-4.

${ }^{3}$ Chief Technologist, Entry Systems and Technologies Division, M/S 229-3, Associate Fellow AIAA.

${ }^{4}$ Graduate Research Assistant, Department of Aerospace Engineering and Mechanics, Student Member AIAA.

${ }^{5}$ Senior Staff Scientist, Entry Systems and Technologies Division, M/S 229-1, Associate Fellow AIAA.

${ }^{6}$ Aerospace Engineer, Atmospheric Flight and Entry Systems Branch, M/S 489, Member AIAA.
} 


$\begin{array}{ll}I_{x x} & =\text { roll axis mass momement of inertia } \\ I_{y y} & =\text { pitch axis mass moment of inertia } \\ I_{z z} & =\text { yaw axis mass moment of inertia } \\ l_{T} & =\text { towline length } \\ q & =\text { dynamic pressure at parachute line stretch } \\ T_{\infty} & =\text { freestream temperature } \\ V_{\infty} & =\text { freestream velocity } \\ x_{c g} & =\text { axial center of gravity location measured from the nose } \\ X_{1} & =\text { parachute force reduction factor } \\ y_{C G} & =\text { pitch direction center of gravity location } \\ z_{C G} & =\text { yaw direction center of gravity location } \\ \rho_{\infty} & =\text { freestream density }\end{array}$

\section{Introduction}

DLAnetary entry vehicles destined for locations other than Earth are often designed such that hardware employed during atmospheric entry for drag augmentation and payload thermal protection are jettisoned. The science payload must be "separated" from the aeroshell prior to impact with the planetary surface (Venus, Mars, Titan) or start of the primary science phase (Saturn, Jupiter, Uranus). This risky event presents a design problem that has been met successfully in past planetary exploration missions using a combination of two technologies: a bluntbody aeroshell and a parachute. Just as a bowling ball falls faster than a feather, a used heat shield (often ballasted with extra mass) falls faster than the science payload attached to a properly-designed parachute.

While the blunt-body aeroshell is an excellent means to reject heat generated at hypersonic speeds, it can become dynamically unstable at low supersonic speeds causing angle-of-attack oscillation amplitude growth. Deployment of a supersonic parachute serves the dual purpose of providing drag augmentation and transforming the entry vehicle into a highly stable two-body dynamic system with a wrist mode. In this way, the aeroshell and parachute system designs are highly coupled by the aeroshell's supersonic dynamic stability characteristics and the parachute system's robustness to high angle-of-attack oscillation amplitude at parachute deployment.

Ensuring a design solution exists for payload separation is a matter of mission feasibility. It is prudent to mitigate payload separation risks in the early stages of hypersonic entry system technology development to avoid levying such risks on future flight projects. A deployable heat shield technology known as the Adaptive Deployable Entry and Placement Technology (ADEPT) is a hypersonic mechanically-deployed aerodynamic decelerator being designed to provide substantial science benefits for the Venus In Situ Explorer (VISE) mission identified in the National Research Council's Decadal Survey. ${ }^{1}$ This mechanically-deployed entry technology was originally developed for human-class Mars exploration missions. ${ }^{2}$ VISE mission benefits and design challenges were assessed through a mission design study where a conceptual science payload, the Venus Intrepid Tessera Lander (VITaL), ${ }^{3}$ was repackaged from a rigid aeroshell into the ADEPT decelerator. The most notable benefit provide by ADEPT for the VISE mission is a reduction of deceleration loads on the science payload by an order of magnitude compared to a rigid aeroshell, enabling the use of more sensitive instruments and offering mass savings. ${ }^{4}$

Payload separation risks are being addressed in the technology development project through a combination of (1) parachute system design, (2) trajectory simulation sensitivity studies and (3) free-flight computational fluid dynamics (CFD) code development. Progress in each element as a means toward separation system design and risk mitigation is discussed in the present paper. The goal of this work is to help advance ADEPT's readiness to a point where the EDL system verification and validation costs absorbed by a future flight project will be less than those of traditional rigid aeroshell.

\section{Venus In Situ Explorer Mission with a Deployable Heatshield}

The baseline ADEPT-VITaL mission concept of operations, detailed in Ref. 4, is intended to support the science objectives and associated instruments onboard the VITaL lander. A lander with a mass of about $1050 \mathrm{~kg}$ will carry the instruments in a pressurized vessel, with a thermal management system that can support three hours of operation, including one hour of descent after separation from the atmospheric entry system and two hours of surface operations. The lander will limit the deceleration loads on the instruments at surface impact, and will provide a stable platform on slopes up to $60^{\circ}$.

The ADEPT decelerator achieves the desired low ballistic coefficient through a $6 \mathrm{~m}$ deployed diameter and a $70^{\circ}$ forebody cone angle. It will carry the payload from entry interface conditions of $10.8 \mathrm{~km} / \mathrm{s}$ and flight path angle of $8.25^{\circ}$ to subsonic parachute deployment at an altitude above $75 \mathrm{~km}$. The baseline design relies on the parachute to

2

American Institute of Aeronautics and Astronautics 
extract the lander from the ADEPT decelerator. VITaL is cut from the parachute once ADEPT has separated a safe distance from the parachute and the probability of re-contact with VITaL is negligible. Readers should refer to Ref. 4 for more detail on the baseline ADEPT-VITaL mission design and details of the ADEPT and VITaL mechanical designs.

\section{Payload Separation System Trade Study}

Several alternative concepts were considered when selecting the baseline payload separation system. Figure 1 shows eight separation architectures considered in this trade study along with the primary reason for rejecting each architecture in favor of the baseline. Two structural configurations were considered: one where VITaL is oriented with landing ring forward (Configuration A) and one where VITaL is oriented landing ring aft (Configuration B). Configuration $\mathrm{B}$ offers a more efficient load path between the cruise stage adaptor, aft ring, and landing ring compared to Configuration A. However, Configuration A offers a clear CG advantage over Configuration B because the relatively massive landing ring is located closer to the nose. Furthermore, Configuration B is considered far riskier than Configuration A because an inversion maneuver is required for the lander.

The baseline separation architecture (A1) uses a subsonic parachute to achieve a lower ballistic coefficient for the VITaL parachute system than ADEPT. An architecture A2 (similar to A1) that first retracts ADEPT before deploying a subsonic parachute to achieve separation was considered. Architecture A2 offers the advantage that the subsonic parachute canopy does not need to be as large nor have as long a towline as the baseline (A1). However, there is nothing about the design of the subsonic parachute in A1 that appears infeasible: nearly all of the design elements are based on heritage designs. The need to retract ADEPT also adds an extra step to the separation sequence and lowers system reliability. Furthermore, any power required to retract ADEPT would need to be drawn from VITaL, which is a clear disadvantage. Note that a supersonic parachute or other drogue device could be substituted or added in architectures A1 and A2 should dynamic stability issues become insurmountable through design of the subsonic parachute system.

Of the eight architectures considered, two architectures, $\mathrm{A} 3$ and $\mathrm{B} 1$, are deemed infeasible because they require an inversion of the ADEPTVITaL entry vehicle at subsonic speeds. This maneuver would be extremely hazardous because

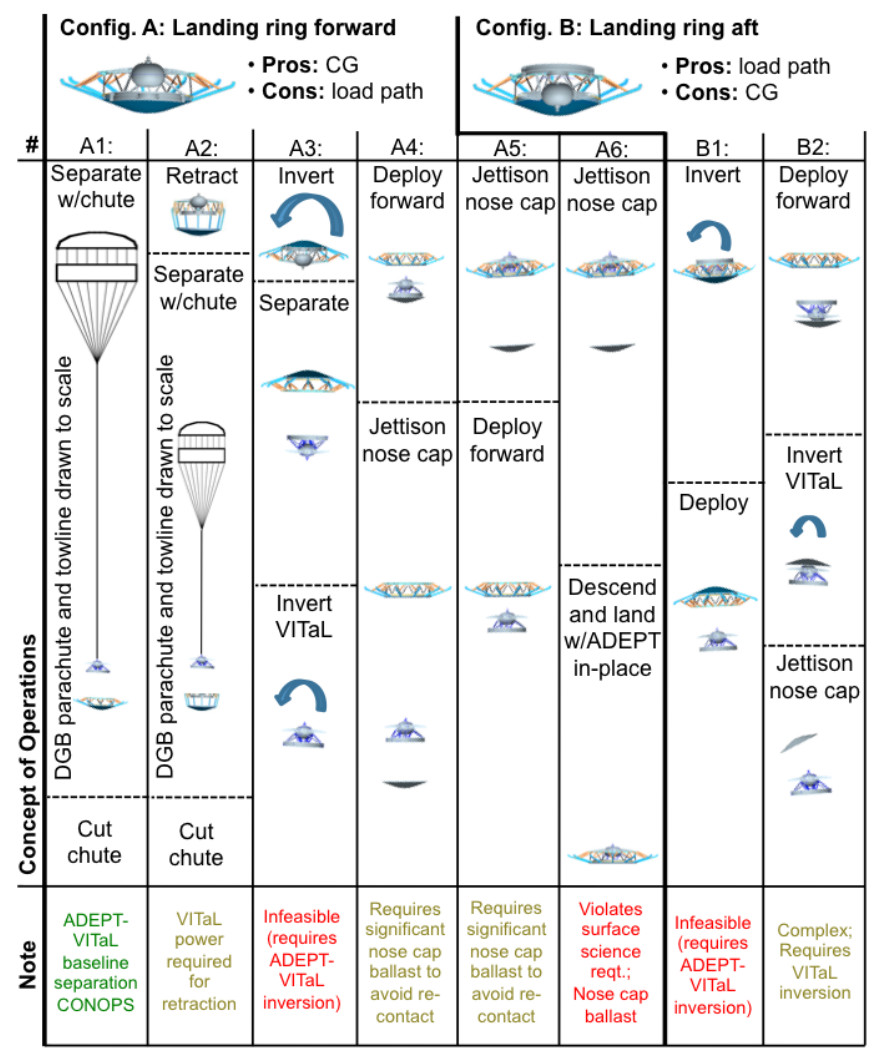

Figure 1. Payload separation architectures considered for ADEPT-VITaL mission. the inverted shape would not be statically stable and would tumble unpredictably. Architecture B2 requires an inversion of VITaL after it has separated. This maneuver is considered unnecessarily risky and complicated given the alternative separation architectures available.

Three architectures, A4, A5, and A6, consider separating VITaL "through the nose" of ADEPT. Architectures A4 and A5 would both require that the nose cap carry a substantial amount of ballast to ensure that its ballistic coefficient is higher than the hardware remaining above. This presents a significant challenge and may even be infeasible considering the nose cap has a mass less than $100 \mathrm{~kg}$ and relatively high drag. Alternatively the nose cap could be ejected into the flow with enough side force to remove it from flight path of the remaining hardware. This option is also considered unnecessarily complicated compared to the baseline separation architecture. One configuration (A6) was considered that lands with ADEPT still attached. This option carries the nose cap ballast complication, but also violates a key science requirement that the instruments have an unobstructed view of the surface adjacent to VITaL. 


\section{Parachute System Design}

\section{A. Separation Concept:}

VITaL is separated from ADEPT using a trailing decelerator system design based on the Pioneer Venus Large Probe (PVLP) subsonic parachute system. PVLP deployed a subsonic conical ribbon main parachute using a ribless guide surface (RGS) pilot parachute that was mortar-deployed from the shoulder of the probe, sideways into the flow (perpendicular to the flight path of the probe). ${ }^{5}$ The PVLP parachute system is clarified in Figure 2.

(a)

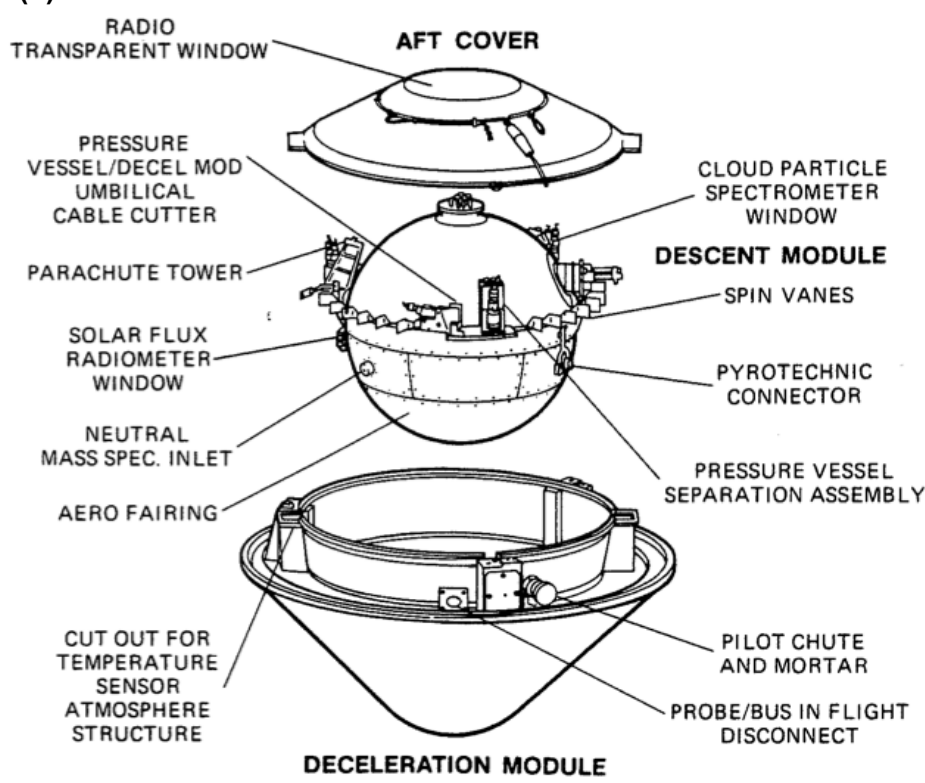

(b)

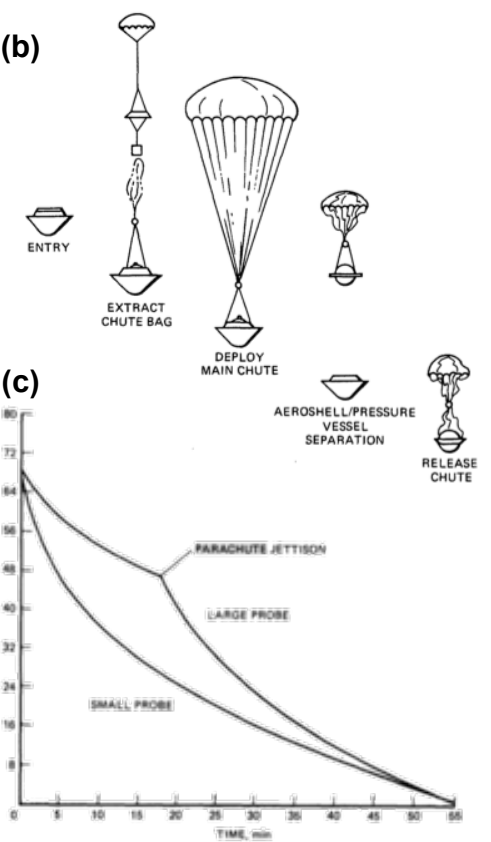

Figure 2. PVLP parachute system. (a) PVLP used mortar mounted near the aeroshell shoulder to deploy a small pilot parachute. The pilot parachute removed the aft cover, which in turn extracted the main parachute. (b) PVLP parachute deployment and probe release scheme. (c) Altitude vs. time profile of PVLP payload compared to the small probes, which did not employ parachutes. ${ }^{5}$

An adaptation of PVLP's parachute system to ADEPT-VITaL is shown in Figure 3. Like PVLP, this system employs a pilot parachute ejected sideways into the flow. A $36 \mathrm{~m}$ towline connects the pilot parachute to the aft cover, and the pilot parachute provides a nominal axial force that extracts the aft-cover from VITaL. The parachute is connected to the aft cover and stowed in a toroidal configuration around the payload's pressure vessel. (One advantage of the PVLP-style parachute system is the main parachute can be stowed in any configuration.) The aftcover also serves the purpose of insulating the pressure vessel from base heating and prevents premature activation of the phase change thermal insulation material. The inflated main parachute provides enough drag to extract VITaL from ADEPT. Separation guide rails allow for quick and smooth extraction of VITaL from the ADEPT structure. At this point VITaL descends under the subsonic parachute for a short period of time until the ADEPT structure is far enough away that the risk of re-contact is negligible. The main parachute is released and VITaL begins its freefall to the surface of Venus. This marks the beginning of VITaL's atmospheric science mission.

\section{B. Subsonic Parachute System Design:}

The parachute design presented is intended to show feasibility of the separation-by-parachute concept. Table 1 summarizes the parachute system design and performance and compares the ADEPT-VITaL parachute system with that of the VITaL baseline, PVLP, and Mars Science Laboratory (MSL). This conceptual parachute design has some traits that are similar to PVLP (concept of operation, peak inflation load, deployment speed), some that are similar to MSL (system mass, deployment dynamic pressure, towline length), and some that are unique to ADEPT-VITaL among planetary probes (combination of subsonic and low dynamic pressure at deployment). This preliminary design shows that there is no compelling reason against the use of a subsonic parachute system to perform 
separation in favor of a more radical and untried method (VITaL release "through the nose", flipping the vehicle and separating, etc.).

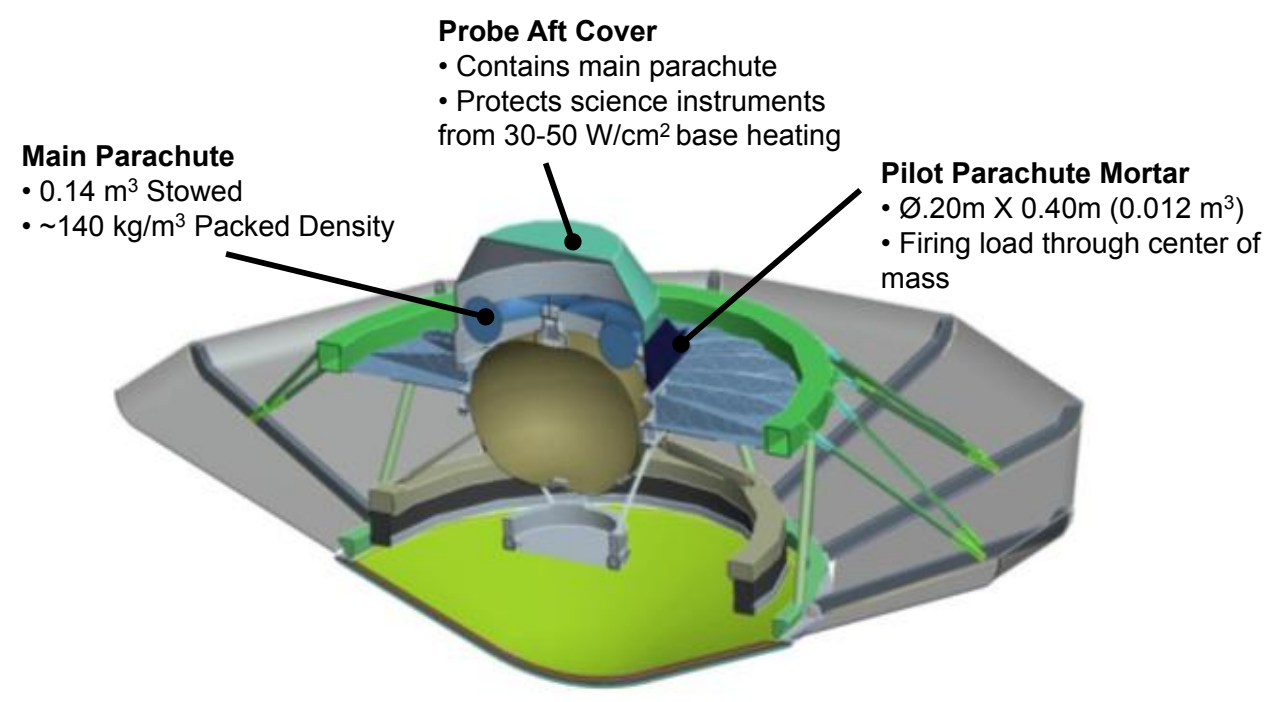

Figure 3. ADEPT-VITaL separation system components: main parachute, aft cover, and pilot parachute mortar. The ADEPT-VITaL separation system is based on PVLP parachute design heritage. 
Table 1. ADEPT-VITaL separation parachute system traits compared with the VITaL baseline, PVLP, and MSL. ${ }^{3,6-8}$

\begin{tabular}{|c|c|c|c|c|}
\hline Parameter & ADEPT-VITaL & VITaL Baseline & PVLP & MSL \\
\hline \multicolumn{5}{|l|}{ Parachute System Design } \\
\hline System concept of operations & $\begin{array}{l}\text { Mortar-deployed } \\
\text { pilot, pilot- } \\
\text { deployed main }\end{array}$ & $\begin{array}{l}\text { Mortar-deployed } \\
\text { pilot, pilot-deployed } \\
\text { main }\end{array}$ & $\begin{array}{l}\text { Mortar-deployed } \\
\text { pilot, pilot-deployed } \\
\text { main }\end{array}$ & $\begin{array}{l}\text { Mortar- } \\
\text { deployed main }\end{array}$ \\
\hline Deployment speed & Subsonic & Subsonic & Subsonic & Supersonic \\
\hline Leading body diameter $(d)$ & $6.0 \mathrm{~m}$ & $3.5 \mathrm{~m}$ & $1.4 \mathrm{~m}$ & $4.5 \mathrm{~m}$ \\
\hline Towline length $\left(l_{T}\right)$ & $36 \mathrm{~m}$ & No data & $7.6 \mathrm{~m}$ & $45 \mathrm{~m}$ \\
\hline$l_{T} / d$ & 6.0 & No data & 5.4 & 10 \\
\hline Main parachute canopy design & Disk-Gap-Band & Conical Ribbon & Conical Ribbon & $\begin{array}{l}\text { Disk-Gap- } \\
\text { Band }\end{array}$ \\
\hline $\begin{array}{l}\text { Main parachute nominal drag } \\
\text { coefficient }\left(\mathrm{C}_{\mathrm{D} 0}\right)\end{array}$ & 0.61 & 0.53 & 0.53 & 0.61 \\
\hline $\begin{array}{l}\text { Main parachute nominal } \\
\text { diameter }\left(D_{0}\right)\end{array}$ & $10.9 \mathrm{~m}$ & No data & $4.94 \mathrm{~m}$ & $21.5 \mathrm{~m}$ \\
\hline $\begin{array}{l}\text { Main parachute projected to } \\
\text { nominal diameter ratio }\left(\mathrm{D}_{\mathrm{p}} / \mathrm{D}_{0}\right)\end{array}$ & 0.72 & 0.70 & 0.70 & 0.72 \\
\hline $\begin{array}{l}\text { Main parachute projected } \\
\text { diameter }\left(D_{p}\right)\end{array}$ & $7.9 \mathrm{~m}$ & No data & $3.46 \mathrm{~m}$ & $15.5 \mathrm{~m}$ \\
\hline \multicolumn{5}{|l|}{ Parachute System Performance } \\
\hline Main parachute drag area $\left(C_{D} A\right)$ & $57.0 \mathrm{~m}^{2}$ & No data & $10.2 \mathrm{~m}^{2}$ & $220 \mathrm{~m}^{2}$ \\
\hline Peak inflation load factor $\left(\mathrm{C}_{\mathrm{x}}\right)$ & 1.86 & No data & 1.05 & 1.86 \\
\hline Dynamic pressure at inflation & $783 \mathrm{~Pa}$ & $2,856 \mathrm{~Pa}$ & $5,050 \mathrm{~Pa}$ & $660 \mathrm{~Pa}$ \\
\hline Peak inflation load & $84 \mathrm{kN}$ & No data & $40 \mathrm{kN}$ & $286 \mathrm{kN}$ \\
\hline Peak G-load at parachute deploy & $5 \mathrm{G}$ & No data & $13 \mathrm{G}$ & $6 \mathrm{G}$ \\
\hline Parachute system mass & $50 \mathrm{~kg}$ & $40 \mathrm{~kg}$ & $9.7 \mathrm{~kg}$ & $57 \mathrm{~kg}$ \\
\hline
\end{tabular}




\section{Parachute System Design}

A $10.9 \mathrm{~m}$ nominal diameter disk-gap-band (DGB) main parachute at a trailing distance of $36 \mathrm{~m}$ is recommended for ADEPT-VITaL. This selection is based on the DGB's merits in several important categories identified by Cruz: ${ }^{8}$ stability, drag, mass, strength, heritage, robustness in a specific application, reliability, cost and ease of fabrication. Pioneer Venus had an extremely difficult stability requirement $\left(<2^{\circ}\right.$ angle of oscillation) that led to the initial selection of an RGS main canopy design. The RGS design experienced failures that could not be easily mitigated, so a conical ribbon main canopy was substituted late in the Pioneer-Venus program with very limited qualification testing prior to flight. Notional images of a conical ribbon parachute and a

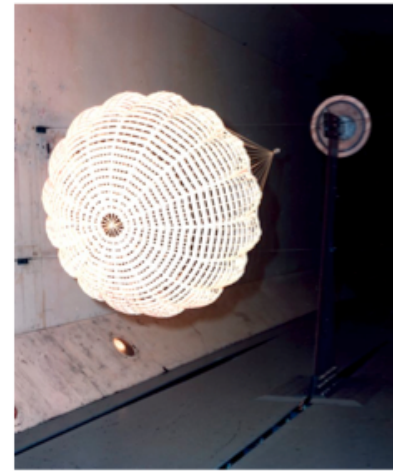

Conical Ribbon

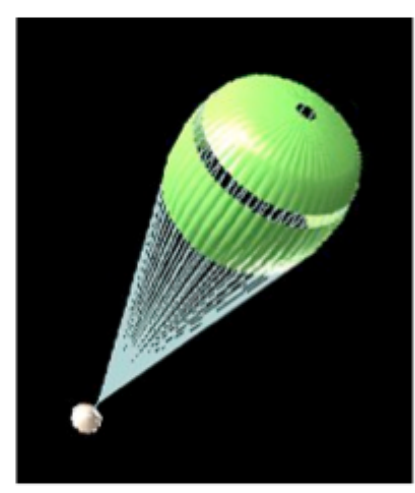

Disk-Gap-Band

Figure 4. Conical ribbon and disk-gap-band parachute. ${ }^{8}$ DGB parachute are shown in Figure 4. At Mars where parachute drag is of paramount importance, a DGB has been the parachute choice in all past U.S. missions. DGB parachutes tend to have more drag than conical ribbon parachutes, but they also tend to be less stable. Recent advancements in Mars exploration programs have led to disk-gap-band (DGB) parachute designs that achieve less than $5^{\circ}$ angle of oscillation. Further improved stability beyond the $5^{\circ}$ angle of oscillation achieved for Mars parachutes is not required for ADEPT-VITaL because stability requirements are placed on the lander after the parachute is cut.

\section{Parachute Performance}

The fully deployed main parachute should be located at a position in the wake of the leading body such that the flow has regained enough momentum to provide the desired drag. Appropriate towline length is a function of the deployment speed (subsonic vs. supersonic) and the diameter of the leading body. ADEPT-VITaL and MSL have a similar towline length $(36 \mathrm{~m}$ vs. $40 \mathrm{~m})$, but for different reasons. ADEPT-VITaL needs the long towline length because of its larger forebody diameter. Optimal towline length should be determined through a trade between parachute system mass and drag. MSL needs the long towline because the flow structure in the wake of a supersonic body requires that the parachute be placed further aft of the leading body compared to subsonic wakes.

The ADEPT-VITaL parachute is sized such that VITaL, with a fully inflated parachute, has a ballistic coefficient that is $80 \%$ that of the ADEPT structure alone immediately after separation, and thus will descent at a slower rate. The parachute sizing assumes that $100 \%$ of the drag of the VITaL + parachute system comes from the parachute. This is the case immediately after separation when VITaL is still in the base flow and is not yet contributing to the total drag. This results in a required parachute drag area $\left(\mathrm{C}_{\mathrm{D}} \mathrm{A}\right)$ of $57.0 \mathrm{~m}^{2}$. A parachute trailing distance of $36 \mathrm{~m}$ is selected based on results of Apollo parachute testing:

"Apollo tests conducted at vertical wind tunnels determined that for vertical descending bodies, the [subsonic] parachute should be ejected to a distance equivalent to more than four times, and preferably six times, the forebody diameter, into good airflow behind the forebody." 6

Figure 5 highlights the relevant parachute test data used to select the trailing distance. The parachute trailing distance for ADEPT-VITaL results in a wake drag loss factor of 0.85 and is near the optimal case for a parachute of this size relative to the forebody as implied by the figure. That is, increasing the towline length beyond 6 forebody diameters results in diminishing returns. 


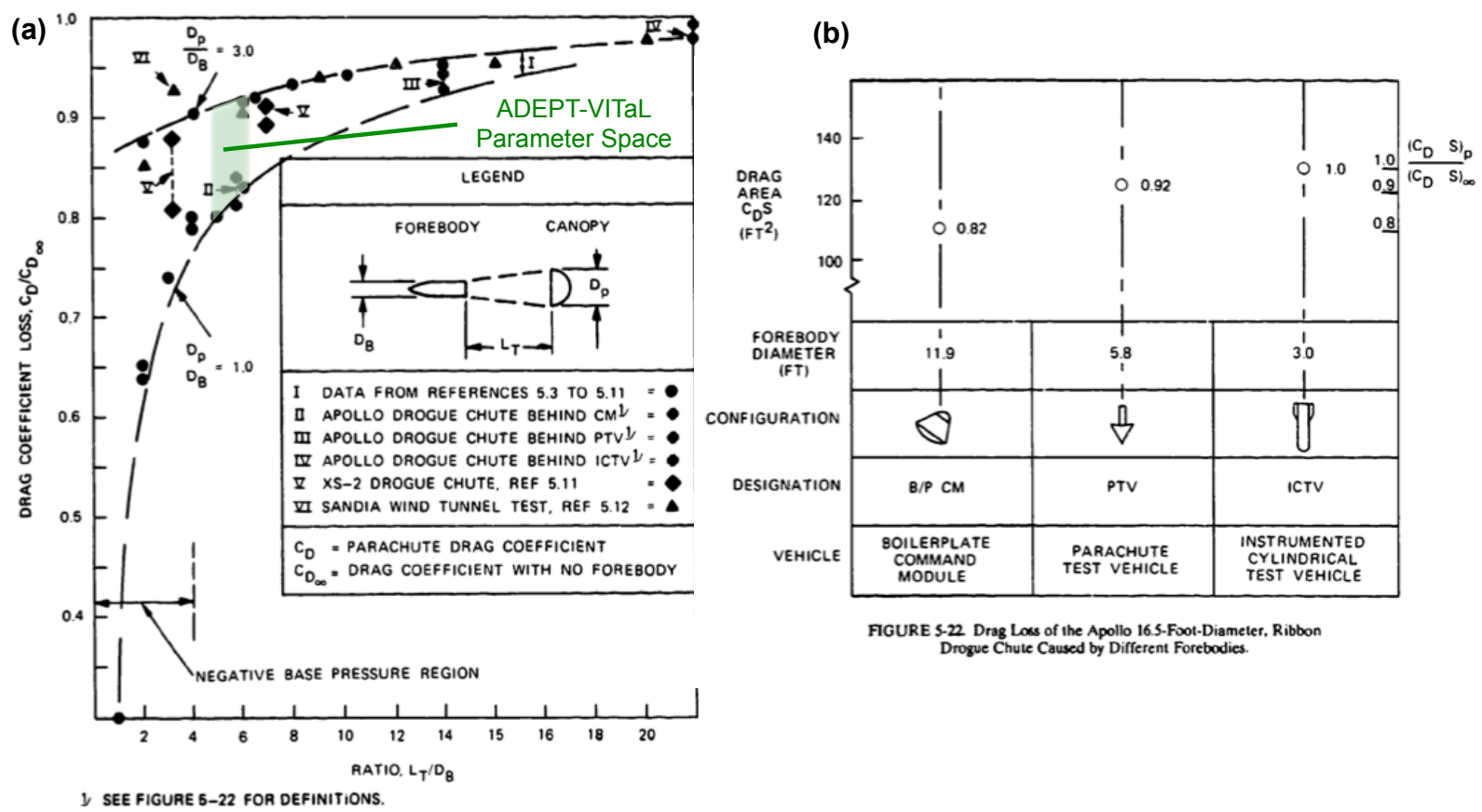

Figure 5. Parachute drag loss caused by subsonic forebody wake. ${ }^{6}$

ADEPT-VITaL decelerates to Mach 0.8 at a higher altitude than a rigid aeroshell (VITaL baseline) because of its lower ballistic coefficient and shallower flight path angle. The difference in atmospheric density at these altitudes is significant, as shown in Table 2. The lower atmospheric density combined with the subsonic speed results in a parachute deployment dynamic pressure for ADEPT-VITaL that is 3.6 times lower than that of the VITaL baseline. Traditional steep entry, high ballistic coefficient Venus entry vehicles experience subsonic parachute deployment dynamic pressures that are a factor of five or greater than Mars missions. Due to its shallow entry and low ballistic coefficient, ADEPT-VITaL achieves subsonic speeds at a higher altitude where the density is lower resulting in greatly reduced deployment dynamic pressure compared to typical Venus probes. The DGB parachute design environment for ADEPT-VITaL is in family with the demonstrated DGB deployment Mach-Q envelope achieved for Mars missions. The ADEPT-VITaL parachute system can leverage heavily form the PVLP heritage (similar concept of operations), Mars Heritage (DGB canopy design), and other recent NASA investments (Low Density Supersonic Decelerator, or LDSD, program).

Table 2. Subsonic parachute deployment conditions for VITaL and ADEPT-VITaL.

\begin{tabular}{lccccc}
\hline \hline & Mach & Altitude & Density & Speed & Dynamic Pressure \\
\hline \hline $\begin{array}{l}\text { VITaL Baseline } \\
\text { (rigid aeroshell) }\end{array}$ & 0.8 & $67.2 \mathrm{~km}$ & $0.140 \mathrm{~kg} / \mathrm{m}^{3}$ & $202 \mathrm{~m} / \mathrm{s}$ & $2,856 \mathrm{~Pa}$ \\
ADEPT-VITaL & 0.8 & $73.8 \mathrm{~km}$ & $0.041 \mathrm{~kg} / \mathrm{m}^{3}$ & $195 \mathrm{~m} / \mathrm{s}$ & $783 \mathrm{~Pa}$ \\
\hline \hline
\end{tabular}

The force on the vehicle from parachute deployment occurs immediately after the main parachute has reached full line stretch and inflation begins. The peak parachute opening force, $F_{p}$, depends on several factors including canopy design, inflation duration, and deployment dynamic pressure. Knacke provides a quick method for estimating a conservative value of the peak parachute opening load using the "W/( $\left.C_{D} A\right)_{p}$ method". ${ }^{6}$ The peak parachute opening force can be estimated as:

$$
F_{p}=\left(C_{D} A\right)_{p} q C_{x} X_{1}
$$

where $\left(C_{D} A\right)_{p}$ is the drag area of the full open parachute, $q$ is the dynamic pressure at line stretch, $\mathrm{C}_{\mathrm{x}}$ is the canopy opening force coefficient at infinite mass, and $\mathrm{X}_{1}$ is a force reduction factor. The force reduction factor is a function 
of canopy loading and varies between near zero for a finite mass inflation (where there is significant deceleration during inflation) and 1.0 for an "infinite mass" inflation (occurs so rapidly that there is no time for deceleration during inflation). A conservative opening force is estimated by assuming the ADEPT-VITaL parachute inflation is infinite mass. The resulting peak parachute inflation load is $84 \mathrm{kN}$, resulting in a sensed deceleration load on the payload of $5 \mathrm{G}$. Note that this deceleration load is much less than ADEPT-VITaL sees at peak deceleration during the hypersonic phase. The parachute line load is significantly lower than MSL because of the smaller canopy size.

\section{E. Mission Feasibility Implications}

This analysis has presented a feasible subsonic parachute system design for separating VITaL from the ADEPT structure. The proposed parachute system design draws many elements from PVLP and MSL heritage. Furthermore, the parachute system can be tested using available and relatively low-cost balloon launch providers such as the Columbia Scientific Balloon Facility through a contract with NASA Goddard's Wallops Flight Facility. In a related study, Clark showed that a parachute deployment condition similar to ADEPT-VITaL can be achieved with the lowest cost CSBF balloon (4.0 million cubic feet): a dynamic pressure of $1 \mathrm{kPa}$ at Mach 0.8 is achieved after 43 seconds of descent by dropping a $726 \mathrm{~kg}$ suspended mass from the balloon at an altitude of $32.8 \mathrm{~km} .^{9} \mathrm{~A} \mathrm{minimal}$ parachute test program will require mortar development, parachute canopy development, and integrated system testing. Witkowsky argues that qualification of a Venus parachute system needed only for separation purposes (and not long-duration drag needs) could be a relatively small effort because the system is only needed for a very short period of time and concerns of atmospheric degradation of materials and stability are not design drivers. ${ }^{10}$

\section{Flight Dynamics Prior to Parachute Deployment}

The parachute system discussed in the previous section must be able to safely deploy in any of the possible vehicle states at Mach 0.8 . The range of possible states must be determined through analysis. The standard approach is to generate a high fidelity database of static aerodynamics and dynamic stability derivatives to be used in 6-DoF Monte Carlo trajectory analysis. Static aerodynamic data from similarly-shaped entry vehicles can often be applied to new entry vehicles for this purpose, but dynamic stability derivatives are more vehicle-specific and must be determined for any new planetary entry vehicle. In the interest of reducing the separation system risks for ADEPT in a more general sense, this section seeks to understand the sensitivity of flight dynamics during the ADEPT-VITaL mission to dynamic stability parameters to help guide future risk reduction testing and analysis. Key findings of the trajectory simulation parameter sensitivity study are presented. Additionally, the application of recent advancements in adaptive grid techniques making possible high fidelity, free-flight CFD simulations is presented. The method shows promise for being able to estimate aerodynamic damping characteristics computationally, as opposed to the traditional means of obtaining the dynamic stability derivatives through ballistic range testing. The technique also allows aerodynamic damping considerations to be a key part of the preliminary vehicle design process as the sensitivity of aerodynamic damping to vehicle geometry modifications and mass properties can be determined.

\section{A. Trajectory Simulation Parameter Sensitivity Studies}

The stability of a blunt-body entry vehicle is determined by three primary characteristics: static aerodynamics $\left(\mathrm{C}_{\mathrm{L}}, \mathrm{C}_{\mathrm{D}}, \mathrm{C}_{\mathrm{m}}\right.$ ), center of gravity $(\mathrm{CG})$ location, and aerodynamic damping parameters (simplified to the $\mathrm{C}_{\mathrm{mq}}$ aerodynamic derivative in this analysis). Static aerodynamics and CG location drive the angle-of-attack trim point and oscillation frequency, and aerodynamic damping drives the rate of total angle-of-attack amplitude growth or decay. Static aerodynamic data specific to the ADEPT-VITaL configuration is presently being computed, and determination of dynamic stability derivatives for the flight configuration is an area of future work. In the absence of this vehicle-specific data, this preliminary investigation examines ADEPT's stability should the vehicle have static aerodynamic characteristics similar to those of a well-characterized entry vehicle, the Mars Phoenix aeroshell. Phoenix deployed a supersonic parachute and was not specifically designed to be dynamically stable below Mach 2 , and ADEPT is expected to have far better dynamic stability characteristics due to reasons discussed at the end of this section. 
All preliminary trajectory analyses were completed using the Program to Optimize Simulated Trajectories II (POST2). Use of the existing Phoenix aerodatabase was possible for this investigation since the Venusian atmosphere is very similar in composition to that of Mars. Both Phoenix and ADEPT are $70^{\circ}$ forebody cone angle blunt bodies and are expected to have similar static aerodynamic characteristics. Since ADEPT enters Venus at a much faster speed than Phoenix entered Mars $(11.5 \mathrm{~km} / \mathrm{s}$ vs. $5.8 \mathrm{~km} / \mathrm{s})$, a modification was made to prevent extrapolation of aerodynamic coefficients above $5.8 \mathrm{~km} / \mathrm{s}$. Despite their disparate entry velocities, portions of the vehicles' flight trajectories in the regime of peak deceleration are similar. Figure 6 compares the atmospheric density and pressure profiles encountered by Mars Phoenix and ADEPT. For flight velocities between $5 \mathrm{~km} / \mathrm{s}$ and $3 \mathrm{~km} / \mathrm{s}$, the dynamic pressure experienced by both vehicles are similar because the atmospheric densities are similar (though altitudes are very different). A final key difference between the Phoenix and ADEPT trajectories is the influence of extremely high wind at Venus on ADEPT's stability: wind speeds can exceed $100 \mathrm{~m} / \mathrm{s}$ in the low supersonic flight regime.
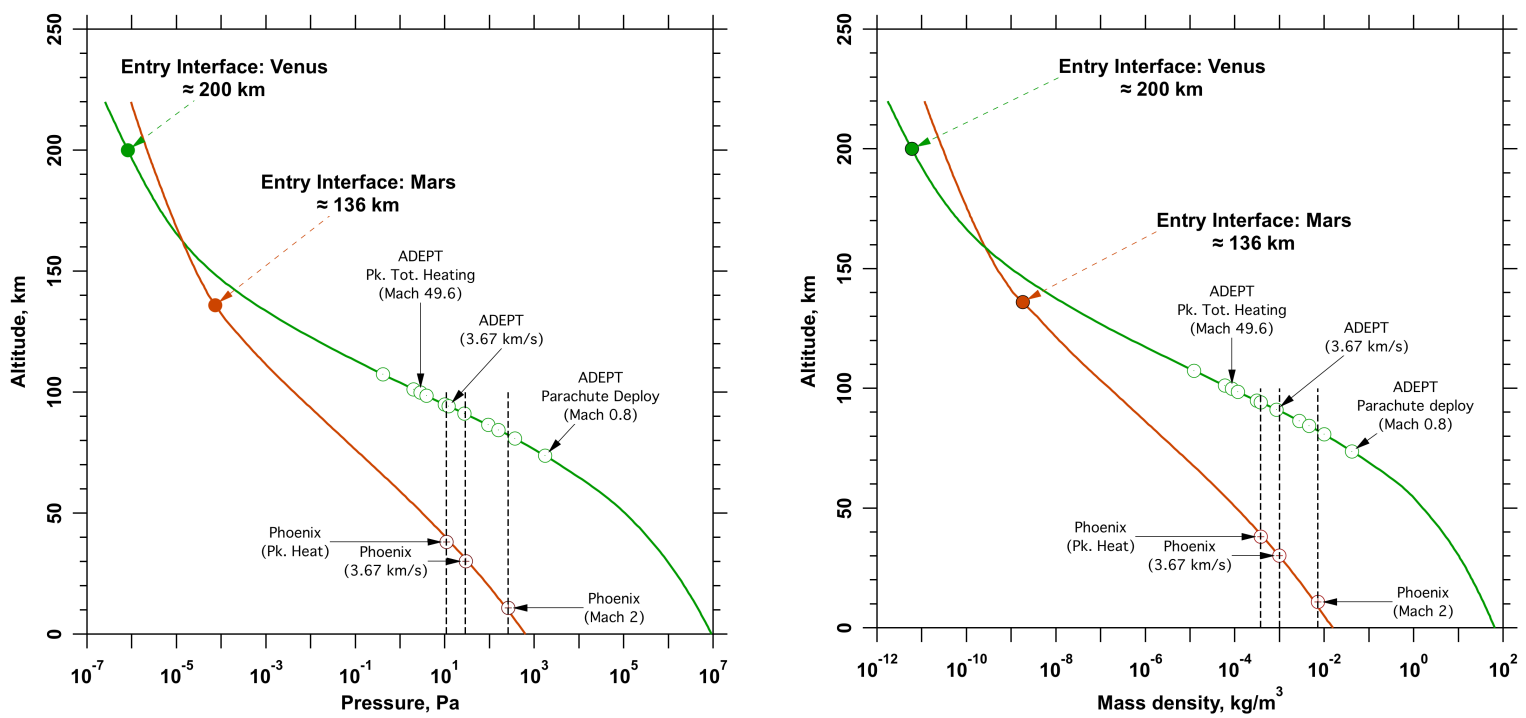

Figure 6. Atmospheric pressure and density comparison for Mars (Phoenix - red line) and Venus (ADEPT - green line) trajectories.

In order to isolate stability effects due to winds and aerodynamic derivatives, four Monte Carlo studies were run, each consisting of 500 POST2 cases. Nominal entry conditions, mass properties, and assumed dispersions are provided in Table 3. All cases prescribe a nominal roll rate of $9 \mathrm{deg} / \mathrm{s}(1.5 \mathrm{rpm})$ at entry interface. This value was chosen as it had the largest impact to the stability in the region from entry interface down to Mach 5 . Below Mach 5 the influence of aerodynamic derivatives and winds overwhelm any favorable impact the initial spin rate has on stabilizing the vehicle through this regime of flight. The first two studies isolate the effects of winds by fixing all aerodynamics to those of the dispersed Phoenix aerodatabase and turning winds on (Case 1) or off (Case 2). Case 3 and Case 4 are a repeat of the first two cases except that aerodynamic derivatives $\left(\mathrm{C}_{\mathrm{mq}}\right)$ are set to zero below Mach 2. Forcing $\mathrm{C}_{\mathrm{mq}}$ to be numerically zero simply means that the total angle-of-attack oscillation amplitude will not be influenced one way or the other by the aerodynamic derivatives. Note that the aerodynamic derivatives are positive (dynamically unstable) in the Phoenix aerodatabase for all time below Mach 2. 
Table 3. Trajectory simulation entry conditions, mass properties, and dispersions.

\begin{tabular}{ccc}
\hline \hline Variable & Nominal & Dispersion \\
\hline \hline Geodetic altitude $(\mathrm{km})$ & 200 & None \\
Flight path angle $\left({ }^{\circ}\right)$ & -8.25 & $+/-0.1$ \\
Velocity $(\mathrm{m} / \mathrm{s})$ & 11,500 & $+/-15$ \\
Pitch, yaw, roll rates $(\mathrm{deg} / \mathrm{s})$ & 0 & $+/-0.4$ \\
$\mathrm{x}_{\mathrm{CG}}(\mathrm{m}$ from the nose $)$ & 1.031 & $+/-0.25$ \\
$\mathrm{y}_{\mathrm{CG}}(\mathrm{m})$ & 0 & $+/-0.01$ \\
$\mathrm{Z}_{\mathrm{CG}}(\mathrm{m})$ & 0 & $+/-0.004$ \\
Mass $(\mathrm{kg})$ & 2,104 & $+/-10 \%$ \\
$\mathrm{I}_{\mathrm{XX}}\left(\mathrm{kg}-\mathrm{m}^{2}\right)$ & 3,060 & $+/-10 \%$ \\
$\mathrm{I}_{\mathrm{YY}}\left(\mathrm{kg}-\mathrm{m}^{2}\right)$ & 1,916 & $+/-10 \%$ \\
$\mathrm{I}_{\mathrm{ZZ}}\left(\mathrm{kg}-\mathrm{m}^{2}\right)$ & 1,922 & $+/-10 \%$ \\
\hline \hline
\end{tabular}

Key results from the four Monte Carlo simulations are provided in Table 4. Comparing the results of cases 1-2 with cases 3-4 below Mach 2 reveals the high importance of the aerodynamic derivatives on ADEPT's stability. It is not unexpected that a hypothetical ADEPT vehicle with Phoenix's aerodynamic derivatives would have a large distribution in angle-of-attack approaching the flight speed of subsonic parachute deployment. Adding the effect of Venusian wind to this hypothetical situation increases the angle-of-attack distribution even higher. It is unclear if the subsonic parachute system described earlier in this paper could reliably deploy at such angles of attack, though sideways-deployed parachute systems are expected to be more robust to high angle-of-attack deployment than Mars aft-deployed parachute systems. Case 3 explores the vehicle dynamics with wind on and $\mathrm{C}_{\mathrm{mq}}$ set to zero below Mach 2. Between Mach 1 and 1.5, the mean total angle-of-attack is a relatively modest $8.4^{\circ}$. It is obvious that the major factor driving total angle-of-attack oscillation amplitude is the value of $\mathrm{C}_{\mathrm{mq}}$ below Mach 2, but the impact of winds is not trivial.

Table 4. Effect of wind and dynamic stability $\left(C_{m q}\right)$ on stability of the ADEPT entry vehicle.

\begin{tabular}{|c|c|c|c|c|c|c|c|c|c|c|c|}
\hline \multicolumn{3}{|c|}{ Case Information } & \multicolumn{3}{|c|}{$\begin{array}{l}\text { Total Angle-of-attack } \\
\text { (Mach } 1 \text { to 1.5) }\end{array}$} & \multicolumn{3}{|c|}{$\begin{array}{l}\text { Total Angle-of-attack } \\
\text { (Mach 1.5 to 2) }\end{array}$} & \multicolumn{3}{|c|}{$\begin{array}{l}\text { Total Angle-of-attack } \\
\text { (Mach } 2 \text { to 5) }\end{array}$} \\
\hline \# & $\begin{array}{c}\mathrm{C}_{\mathrm{mq}} \\
(\mathrm{Mach}<2) \\
\end{array}$ & Wind & Std. Dev. & Mean & Median & Std. Dev. & Mean & Median & Std. Dev. & Mean & Median \\
\hline 1 & Phoenix & On & 16.4 & 52.2 & 49.6 & 5.82 & 12.6 & 11.4 & 1.86 & 4.24 & 3.83 \\
\hline 2 & Phoenix & Off & 15.4 & 31.7 & 28.8 & 2.01 & 1.98 & 1.56 & 0.68 & 1.47 & 1.45 \\
\hline 3 & 0 & On & 3.66 & 8.40 & 7.58 & 2.68 & 5.53 & 4.91 & 1.88 & 4.25 & 3.85 \\
\hline 4 & 0 & Off & 0.62 & 1.17 & 1.08 & 0.63 & 1.31 & 1.25 & 0.68 & 1.47 & 1.45 \\
\hline
\end{tabular}

It has been theorized that a large contribution to the dynamic instability observed in $70^{\circ}$ sphere cones like Phoenix comes from wake flow phenomena caused by the shape of aft aeroshell, or backshell. ${ }^{11}$ A caveat of using the Phoenix aerodatabase is that Phoenix had a backshell whereas ADEPT has a flat base and a sharp shoulder. These differences imply that Phoenix and ADEPT have significantly different wake flow fields and shoulder flow patterns, and thus have significantly different aerodynamic derivatives. Recent ground experiments of the Inflatable Reentry Vehicle Experiment (IRVE) in the Eglin ballistic range and flight tests (IRVE-2 and IRVE-3) have shown that $60^{\circ}$ sphere cone geometries without a backshell protruding into the flow may be much more stable than traditional Mars aeroshells. IRVE has a similar backshell shape as ADEPT but is a less blunt $60^{\circ}$ sphere cone rather than the $70^{\circ}$ of ADEPT. Future work in the area of POST2 trajectory simulation will entail using ADEPT's static aerodatabase and IRVE-3's aerodynamic derivatives to obtain a more complete picture of the true stability of this vehicle.

\section{B. Free-Flight Computational Fluid Dynamics}

Recent efforts toward developing a capability for performing free-flight, high-fidelity, CFD simulations may yield further insight into potential instability phenomena. This capability has been implemented in the UnStructured 
3D (US3D) computational fluid dynamics code. US3D is a parallel, unstructured, Navier-Stokes solver developed at the University of Minnesota. The free-flight simulation capability has been enabled by recent developments in performing fluid structure interaction (FSI) simulations using this code. ${ }^{12} \mathrm{FSI}$ simulations require the ability to move the computational mesh to accommodate a deforming structure. In the case of free-flight CFD, we use the same idea, however in this case the capsule structure is rigid but allowed to freely rotate within the deforming mesh. ${ }^{13} \mathrm{An}$ example of this mesh deformation method being used to simulate the free rotation of a notional ADEPT geometry is shown in Figure 7.

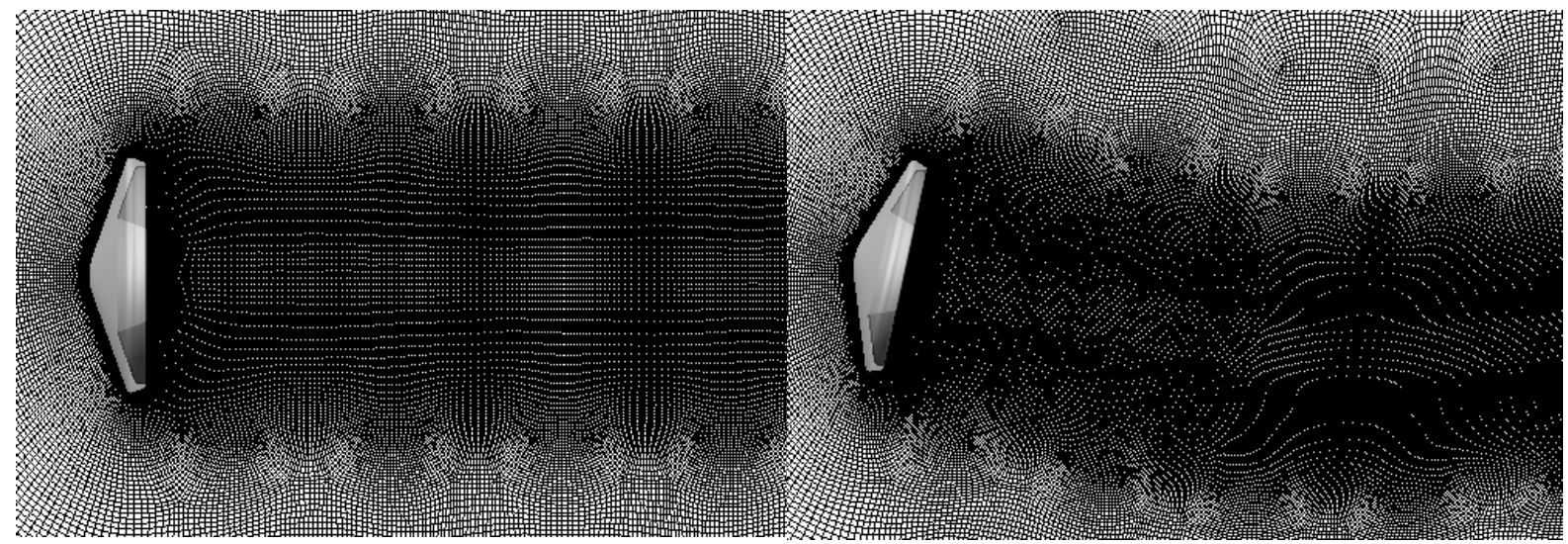

Figure 7: Example of rigid body rotation within a deforming mesh. The figure on the left shows a notional ADEPT geometry at $0^{\circ}$ angle-of-attack, while the figure on the right is for an angle-of-attack of $15^{\circ}$.

The translational degrees of freedom are treated by solving the governing equations in a moving reference frame. In principle, by combining these two methods, we can perform 6-DoF simulations of entry vehicles while resolving the fluid physics with a high degree of fidelity. This level of fidelity is necessary to resolve the complex fluid dynamics in the unsteady wake, which is thought to contribute to dynamic instability phenomena. It is hoped that this tool will facilitate investigation of the influence of the wake flow on the dynamic stability of open-backed aeroshell shapes, such as ADEPT.

In addition to yielding insight into the physical phenomena influencing the aerodynamics, we might also be able to use this tool to compute dynamic stability derivatives (i.e. $\mathrm{C}_{\mathrm{mq}}$ ) used in trajectory modeling. To demonstrate this, we have run trajectory simulations on a notional ADEPT geometry with the mass properties in Table 3 . In these cases, we have constrained the motion to a single rotational degree of freedom (1-DoF) in order to simplify the analysis, and thus here the pitch angle and the angle-of-attack are identical. The freestream Mach number has been held constant at 0.8 , since this is likely to be the most unstable regime prior to parachute deployment. Figure 8 shows angle-of-attack trajectories from these simulations for initial angles of attack of 5 and 20 degrees. We can observe from this plot that the simulation predicts the oscillations to be damped for the higher amplitude motion, while we see some slight amplitude growth or possibly neutrally stable

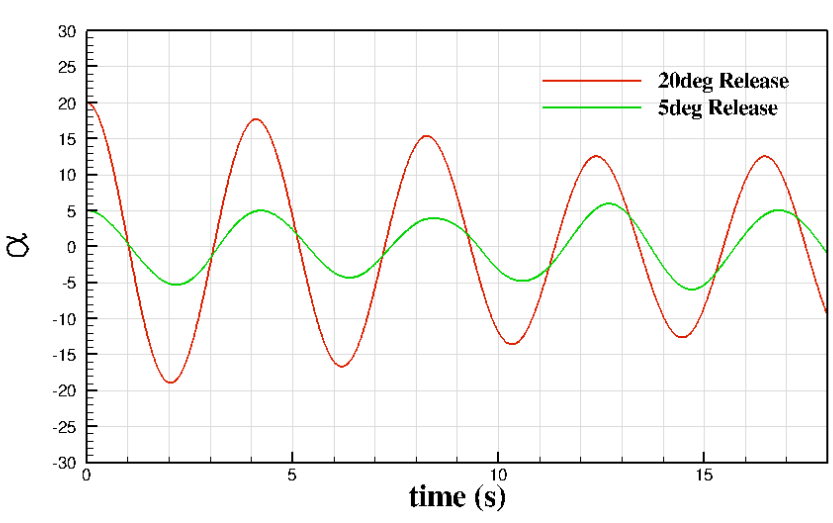

Figure 8. Angle-of-attack trajectories for a notional ADEPT geometry at Mach 0.8 . The red and green curves show initial amplitudes of 20 and 5 degrees, respectively. Free stream conditions for this simulation are: $\rho_{\infty}=0.0182 \mathrm{~kg} / \mathrm{m}^{3}, T_{\infty}=205.7 \mathrm{~K}, V_{\infty}=195 \mathrm{~m} / \mathrm{s}$. behavior in the case of the low amplitude motion.

Using this trajectory data, we can use linear regression to estimate the value of $\mathrm{C}_{\mathrm{mq}}$ at small increments of the angle-of-attack. The results of this analysis can be seen in Figure 9. In this plot we can see greater dispersion in the pitch damping estimates for the low-amplitude motion, while the high-amplitude motion has a fairly level, and 


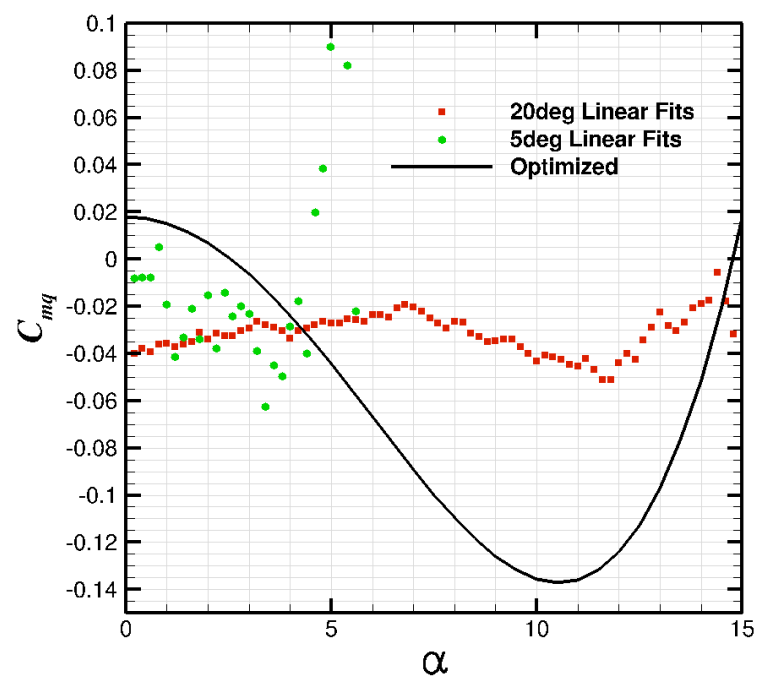

Figure 9. Computed pitch damping from CFD predicted trajectories. The green and red symbols show linear regression fits for the low and high amplitude trajectories respectively. The solid black curve is obtained using a model parameter optimization.

growth in the higher amplitude case likely attributable to a frequency mismatch due to model assumptions.

The case presented here is intended as a demonstration of how free-flight CFD might be used to estimate dynamic derivatives for ADEPT. Future work will focus on leveraging the full 6-DoF capability, not only for computing dynamic derivatives, but also for undertaking sensitivity studies. The tool could be used to investigate the effect of geometric parameters such as shoulder radius, cone angle, and aft-body geometry. The effect of mass properties such as CG location, and moments of inertia will also be examined using this capability.
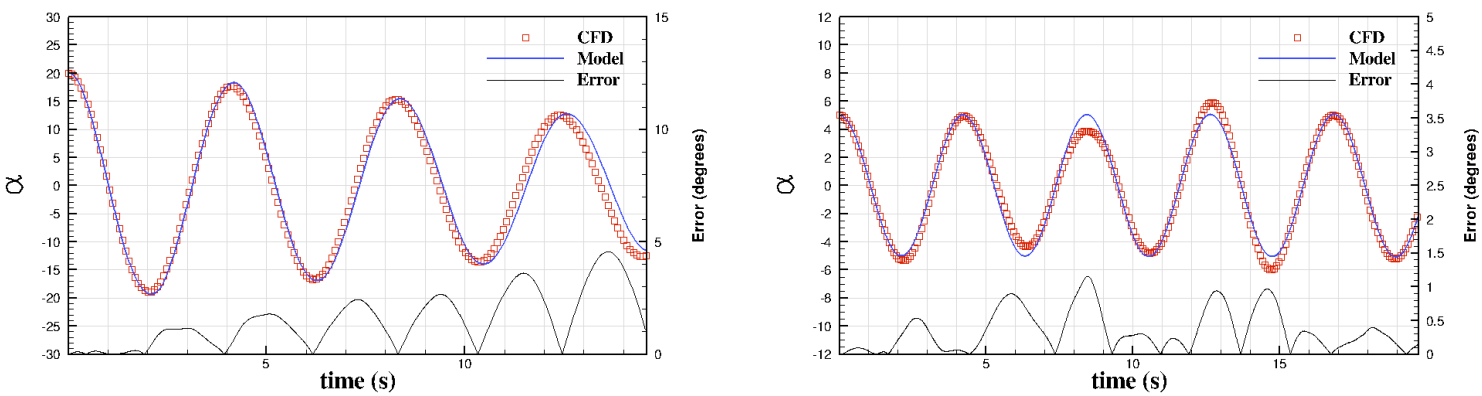

Figure 10. Comparison of the trajectories computed from free-flight CFD (red symbols) to those created using the model (blue line) for both the high initial amplitude (left) and low initial amplitude (right).

\section{Conclusions}

Progress has been made reducing the risk of separating a conceptual VISE payload from ADEPT: a low ballistic coefficient mechanically-deployed heatshield. The intent of this study is to ease mission implementation of ADEPT through early conceptual system design, trajectory sensitivity studies, and maturation of CFD analysis techniques. This paper has described the baseline payload separation system design for the ADEPT-VITaL mission and results of analyses to date.

The baseline subsonic parachute separation system was selected after considering several alternatives and qualitatively weighing their positives and negatives. The conceptual subsonic parachute system design employs a mortar-deployed pilot parachute ejected sideways into the flow, which is used to extract the aft cover and main parachute from a toroidal bag surrounding the science payload. The shallow entry flight path angle causes the 
vehicle to decelerate to subsonic speeds at an altitude where the deployment dynamic pressure is relatively low compared to typical planetary subsonic parachutes. Parachute deployment loads for the baseline DGB parachute are in family with well-characterized supersonic Mars parachutes. The ADEPT parachute system can leverage heavily from PVLP and Mars parachute system design heritage and can be qualified for flight using conventional ground testing techniques.

The subsonic parachute system must be designed to deploy while the vehicle undergoes angle-of-attack oscillations. The amplitude of these oscillations is determined by the dynamic stability characteristics of the entry vehicle. A trajectory sensitivity study using POST2 explores the importance of ADEPT's dynamic stability characteristics on the subsonic vehicle dynamics. It is concluded that dynamic stability characteristics and Venusian winds are important factors influencing subsonic dynamics, and entry spin rate does not influence vehicle dynamics below Mach 5. Applying an aerodynamic model with zero damping instead of positive damping (unstable) below Mach 2 shows angle-of-attack oscillations believed to be manageable by the subsonic parachute system. IRVE flight tests have suggested that flat base geometries may be far more stable than aeroshells with substantial backshells, and future work will explore the effect of more favorable aerodynamic damping characteristics on ADEPT's flight dynamics. Results of the trajectory sensitivity studies will be used to levy requirements on a subsonic parachute system robust to the off-nominal angle-of-attack at parachute deployment.

A validated free-flight CFD capability that can reliably predict pitch damping behavior has high potential to aid the design of ADEPT and other planetary entry vehicles. Exploratory simulations of a notional ADEPT geometry at Mach 0.8 show the vehicle with an oscillation limit cycle near $5^{\circ}$ angle-of-attack. These simulations are a demonstration of how free-flight CFD might be used to estimate dynamic derivatives for ADEPT. The free-flight CFD capability can be used to investigate the effect of geometry refinements to parameters such as shoulder radius, cone angle, and aft-body geometry.

\section{Acknowledgments}

The ADEPT Project was funded by the Game Changing Technologies Division of the NASA Space Technology Program. Dinesh Prabhu was supported by Contract NNA10DE12C from the Entry Systems and Technology Division to ERC, Inc. Eric Stern was supported by NASA Space Technology Research Fellowship \#NNX11AN42H.

\section{References}

${ }^{1}$ Squyres, S. et al., "Visions and Voyages for Planetary Science in the Decade 2013-2022 (Decadal Survey)," The National Academies Press, Washington, D.C., 2011.

${ }^{2}$ Venkatapathy et al., "A Feasibility Study of a Low Ballistic Coefficient, Mechanically Deployable, Semi-Rigid and Transformable Concept (previously called as TEST) for Human Missions to Mars," 21st AIAA Aerodynamic Decelerator Systems Technology Conference and Seminar, AIAA 2011-2068, Dublin, Ireland, June 2011.

${ }^{3}$ Gilmore, M.S. et al., "Venus Intrepid Tessera Lander: Mission Concept Study Report to the NRC Decadal Survey Inner Planets Panel," NASA GSFC and NASA ARC, April 2010.

${ }^{4}$ Smith, B.P. et al., "Venus In Situ Explorer Mission Design using a Mechanically Deployed Aerodynamic Decelerator," IEEE Aerospace Conference, Big Sky, MT, March 2013.

${ }^{5}$ Fimmel, R.O., Colin, L., Burgess, E., "Pioneer Venus," NASA SP-461, 1983.

${ }^{6}$ Knacke, T.W., "Parachute Recovery Systems Design Manual," Naval Weapons Center, NWC TP 6575, China Lake, CA, March 1991.

${ }^{7}$ Sengupta, A., Sinclair, R., Machin, R., "Ringsail Parachutes for Planetary Entry Applications," IEEE Aerospace Conference, Big Sky, MT, March 2011. 2009.

${ }^{8}$ Cruz, J.R., "Aerodynamic Decelerators," Graduate Course Notes from Georgia Tech Planetary Entry and Descent Class,

${ }^{9}$ Clark, J.J., Spencer, D.A., "Design of a High Altitude Balloon Drop Test for SPORE (Small Probes for Orbital Return of Experiments)," Georgia Tech Masters Project, May 2012.

${ }^{10}$ Witkowsky, A., Venkatapathy, E., Zell, P., Allen, G., “Aerodynamic Decelerators for Modern Venus Probes/Landers,” $7^{\text {th }}$ International Planetary Probe Workshop, Barcelona, Spain, June 2010.

${ }^{11}$ Kazemba, C.D., Braun, R.D., Clark, I.G., Schoenenberger, M., "Survey of Blunt Body Dynamic Stability in Supersonic Flow," AIAA Atmospheric Flight Mechanics Conference, AIAA 2012-4509, Minneapolis, MN, August 2012.

${ }^{12}$ Gidzak, V., Candler, G. V., "Validation of Fluid-Structure Interaction Capabilities in US3D," 21st AIAA Aerodynamic Decelerator Systems Technology Conference and Seminar, AIAA 2011-2543, Dublin, Ireland, June 2011.

${ }^{13}$ Stern, E., Gidzak, V., Candler, G. V., "Estimation of Dynamic Stability Coefficients for Aerodynamic Decelerators Using CFD”, AIAA Applied Aerodynamics Conference, AIAA 2012-3225, New Orleans, LA, June 2012 